\title{
'n Ondersoek na die aanwending van mikrorekenaarstelsels in klein sakeondernemings in Suid-Afrika
}

\author{
P.J.S. Bruwer \\ Nagraadse Skool vir Bestuurswese, PU vir CHO, Potchefstroom
}

C.E. Pretorius

Rekenaardienste, PU vir CHO, Potchefstroom

\begin{abstract}
An investigation into the use of microcomputer systems in small businesses in South Africa The relatively low cost and great advantages, i.e. accuracy, time and cost savings, better decision making, more professional service to clients, etc. make a microcomputer system an attractive aid for any business and particularly for the small business. This is why microcomputers will, today and in future, play an everincreasing role in the business world. The implementation of a microcomputer system, however, implies major changes for the business and these changes may create major problems for the management of the small business. The objectives of this research project are to determine the extent to which microcomputer systems are used in small businesses in South Africa, what problems they experience with these systems, and to suggest possible solutions to these problems. Furthermore, the major contributing factors to the successful application of microcomputer systems in small businesses are identified by using regression techniques.
\end{abstract}

S. Afr. J. Bus. Mgmt. 1986, 17: 125-129

Die relatief lae koste en die geweldige voordele akkuraatheid, tydbesparing, kostebesparing, beter besluitneming, meer professionele diens aan kliënte, ens. maak' $n$ mikrorekenaarstelsel 'n baie aantreklike hulpmiddel vir enige sakeonderneming en in besonder vir die klein sakeonderneming. Om dié rede speel mikrorekenaars vandag en sal dit ook in die toekoms ' $n$ al hoe groter rol speel in die besigheidswêreld. Die implementering van 'n mikrorekenaarstelsel beteken egter groot veranderings vir 'n sakeonderneming en hierdie veranderings kan groot probleme vir die bestuur van die klein sakeonderneming skep. Die doel van hierdie navorsingsprojek is om vas te stel tot watter mate mikrorekenaars in klein sakeondernemings in Suid-Afrika aangewend word, watter probleme daar met sodanige stelsels ondervind word en om moontlike oplossings daarvoor aan te beveel. Verder word die belangrikste bydraende faktore tot die suksesvolle aanwending van mikrorekenaarstelsels in klein sakeondernemings geïdentifiseer deur van regressiemetodes gebruik te maak. S.-Afr. Tydskr. Bedryfsl.. 1986, 17: 125-129

\footnotetext{
P.J.S. Bruwer*

Nagraadse Skool vir Bestuurswese, PU vir CHO,

Potchefstroom, 2520 Republiek van Suid-Afrika

C.E. Pretorius

Rekenaardienste, PU vir $\mathrm{CHO}$,

Potchefstroom, 2520 Republiek van Suid-Afrika

*Aan wie korrespondensie gerig moet word

Ontvang Mei 1986
}

\section{Inleiding}

Die geweldige vordering in rekenaartegnologie het gelei tot die bekendstelling van die mikrorekenaar in die middel 1970s. Sedertdien het die verwerkingskrag, -spoed en stoorkapasiteit van mikrorekenaars geweldig toegeneem terwyl die koste daarvan relatief laag gebly het. Dit het veroorsaak dat die mikrorekenaar 'n baie aantreklike hulpmiddel vir veral die klein sakeman geword het. In 'n toenemende mate het die mikrorekenaar dan ook sy vastrapplek in klein sakeondernemings begin kry. Volgens die Adviesburo vir Klein Sakeondernemings word die klein sakeonderneming gedefinieer as ' $n$ onderneming wat onafhanklik besit, bestuur en bedryf word, nie meer as R0,5-5 miljoen omset (afhangende van die bedryf) realiseer nie, nie meer as 100 werknemers in diens het nie, oor nie meer as $\mathbf{R} 1$ miljoen se bates (grond en geboue uitgesluit) beskik nie, en nie meer as vyf bedryfseenhede (takke) het nie. 'n Onderneming is klein as dit aan minstens vyf van hierdie riglyne voldoen.

Waar daar in die verlede veral gesteun is op die handverwerking van data met betrekking tot transaksieverwerkingstelsels soos debiteure, krediteure, voorraadbeheer, ens., is die tendens baie vinnig besig om te verander in die sin dat die lae koste van die mikrorekenaar die klein sakeman in ' $n$ toenemende mate in staat stel om sy eie rekenarisering te bekostig om hierdie roetine-tipe-take baie akkuraat en vinnig te verrig. Dit is egter ongelukkig ook so dat hierdie verandering talle probleme vir die bestuur van 'n klein sakeonderneming kan meebring en die oorsake van hierdie probleme is nie altyd maklik identifiseerbaar nie. Vele probleme kan ontstaan indien die bestuur nie die regte stappe neem alvorens hy wil rekenariseer nie. Daar is ook 'n hele aantal basiese stappe wat gevolg moet word ná die implementering van die mikrorekenaar.

In hierdie navorsingsprojek is daar gepoog om probleemareas te identifiseer, moontlike oplossings te verskaf en deur middel van empiriese data te bepaal watter faktore die grootste rol speel in die suksesvolle aanwending van mikrorekenaarstelsels in klein sakeondernemings in SuidAfrika.

\section{Voorondersoek}

'n Voorondersoek is geloods om vas te stel of dit enigsins sinvol sou wees om die ondersoek op nasionale vlak te onderneem. Die studiepopulasie van die voorondersoek het die volle populasie van mikrorekenaargebruikers in klein sakeondernemings in drie plattelandse dorpe gedek. Data is deur middel van onderhoudvoering en twee vraelyste - een 
vir die bestuurder van die onderneming en een vir die operateur/trise van die mikrorekenaarstelsel - ingesamel.

'n Paar interessante gevolgtrekkings wat uit hierdie projek voortgespruit het, is die volgende:

(i) Die gebruik van mikrorekenaarstelsels vir kommersiële toepassings in klein sakeondernemings is tans nog besig om deur baie groeipyne te gaan.

(ii) 'n Groot bydraende faktor tot die suksesvolle aanwending van die stelsel is die mate van kundigheid wat daar onder die meeste bestuurders in klein sakeondernemings omtrent die rekenaar en sy vermoëns bestaan.

(iii) Faktore soos probleme wat met mikro's ondervind word, die kostebesparingsaspek, die agent se voorstelling van die mikro, addisionele uitgawes, ens., kan 'n belangrike bydrae tot die welslae van so 'n mikrorekenaarstelsel lewer.

(iv) Laastens kan gemeld word dat die probleme wat met mikrorekenaarstelsels ondervind word, grootliks uitgeskakel kan word indien die bestuurders en gebruikers van die stelsels bereid is om een of ander vorm van rekenaaropleiding te ondergaan.

\section{Insameling van data}

Omdat daar in hierdie navorsingsprojek net van vraelyste gebruik gemaak is wat per pos na die verskillende klein sakeondernemings uitgestuur is, is daar ' $n$ deelversameling van die vrae wat in die voorondersoek gebruik is, in die vraelys ingesluit. Slegs die vrae wat bygedra het tot die afleidings en die gevolgtrekkings uit die voorondersoek en sekere ander vrae soos die tipe mikro wat gebruik word, die koste van rekenaartoerusting en 'n paar houdingsvrae wat op 'n 7-puntskaal beantwoord moes word, is ingesluit. (Hierdie tipe vrae is al in die verlede suksesvol in navorsingsprojekte gebruik - Bruwer, 1983; Bruwer, Pretorius \& Steyn, 1983; Bruwer, 1984a, 1984b; Lucas, 1975). Die rede hiervoor is dat die vraelys so kort en bondig as moontlik gemaak moes word sodat 'n redelike respons verkry kon word.

'n Adreslys en etikette van 'n ewekansige steekproef van 5000 klein sakeondernemings in Suid-Afrika is vanaf die Buro vir Marknavorsing, Universiteit van Suid-Afrika in Pretoria verkry. $\mathrm{Om}$ 'n idee te probeer verkry omtrent die persentasie klein sakeondernemings wat reeds van mikrorekenaars gebruik maak is daar vervolgens 'n ewekansige steekproef van 500 uit die 5000 getrek en 'n vraelys met net 'n enkele vraag, naamlik of die onderneming van 'n mikrorekenaar gebruik maak of nie, is uitgestuur. 'n Respons van $27 \%$ is terugontvang met $18,5 \%$ van die ondernemings wat wel mikrorekenaars gebruik. Omdat die waarskynlikheid groot is dat 'n baie groot persentasie van die nie-respondente nie oor mikrorekenaarstelsels beskik nie, is hierdie syfer as 'n oorskatting van mikrorekenaargebruikers in klein sakeondernemings in Suid-Afrika gesien. As poging om te verseker dat genoeg vraelyste terugontvang sou word sodat sinvolle verwerking gedoen kan word, is vraelyste na al die oorblywende 4500 adresse uitgestuur.

$\mathrm{Na}$ ongeveer twee maande is geen verdere voltooide vraelyste terugontvang nie en was die respons in hierdie geval $23,3 \%$ met $14,6 \%$ van die respondente wat wel van mikrorekenaarstelsels gebruik maak. Die outeurs is van mening dat hierdie syfer ook eerder 'n oorskatting as 'n onderskatting van mikrorekenaargebruikers in klein sakeondernemings in Suid-Afrika kan wees. Die rede wat hiervoor aangevoer kan word, is die feit dat besighede wat nie oor 'n mikrorekenaarstelsel beskik nie, moontlik meer traag was om op die vraelys te reageer. Hierdie is egter ske 'n aanname wat gemaak word en geen inligting kan voorgetk word om dit te bewys nie. 'n Gevoel van die outeur is dan hoogstens $12 \%$ van alle klein sakeondernemings in Suid. Afrika wel van mikrorekenaarstelstels gebruik maak.

\section{Statistiese ontleding van die data}

Tabel 1 bevat die name van die veranderlikes vir die vra wat in die vraelys gebruik is, met die betekenis van elte veranderlike.

Tabel 1 Veranderlikes gebruik in die projek

\begin{tabular}{|c|c|}
\hline Veranderlike & Betekenis \\
\hline 1. SOORT & Tipe mikro \\
\hline 2. $\mathrm{KOS}$ & Koste van die rekenaarstelsel \\
\hline 3. REDE & Hoofrede vir die aankoop van die rekenaar \\
\hline 4. PROB1 & $\begin{array}{l}\text { Hoe lank na die aankoop van die stelsel die cerste } \\
\text { probleme ondervind is }\end{array}$ \\
\hline 5. $\mathrm{PROB} 2$ & Tipe probleme wat ondervind is \\
\hline 6. VERG & Of die rekenaar die bestuurder se werk vergemaklit \\
\hline 7. OPLl & Hoogste vlak van rekenaaropleiding \\
\hline 8. OPL2 & $\begin{array}{l}\text { Hoeveelheid opleiding ontvang om die stelsei te } \\
\text { gebruik }\end{array}$ \\
\hline 9. TEVREDE & Mate van tevredenheid met die stelsel \\
\hline 10. ADMIN & $\begin{array}{l}\text { Mate waartoe die stelsel tot administratiewe } \\
\text { werksvermindering bygedra het }\end{array}$ \\
\hline 11. PERSB & Of personeel met die stelsel bespaar is \\
\hline 12. KOSTE & Of die stelsel 'n kostebesparing teweeg gebring hat \\
\hline 13. AGENT & $\begin{array}{l}\text { Tot watter mate die rekenaarstelsel aan die agentse } \\
\text { voorstelling daarvan voldoen }\end{array}$ \\
\hline 14 BESL & $\begin{array}{l}\text { Tot watter mate die uitvoer van die rekenaar vir } \\
\text { besluitnemingsdoeleindes aangewend word }\end{array}$ \\
\hline
\end{tabular}

\section{Frekwensies}

Met die verwerking en statistiese ontleding van die data is daar hoofsaaklik van BMDP-progammatuur (Dixon \& Brown, 1981) gebruik gemaak. Figure 1-5 is grafiese voorstellings van die respons op vrae wat interessante resultate opgelewer het soos die tipe mikro's wat gebruil word, die koste van die stelsel, die hoofrede vir die aankoop van die mikro, tydsverloop voordat die eerste probleme ondervind is en die hoeveelheid opleiding wat die be stuurders omtrent die stelsel wat hulle gebruik, ontvang het.

\section{Tipe mikrorekenaarstelsels wat gebruik word}

Die mikrorekenaars wat die algemeenste voorgekom het in hierdie steekproef was Commodore $(25,7 \%)$, Apple (18\%), IBM PC $(8 \%)$, Sharp $(6 \%)$, Olivetti $(5,3 \%)$ en Phillips $(4 \%)$. Die ander mikrorekenaars wat gebruik word se individuele bydraes was minder as $1 \%$ en daarom is hulle nie hierby ingesluit nie. Bekende name soos: Canon, $\mathrm{ICl}$, Wang, Radio Shack, NCR, Burroughs, BBC, Hewlett Packard, ens., vorm almal deel van die $33 \%$ wat nie individueel op die grafiek voorkom nie.

Dit behoort interessant te wees om nou na Apple se onttrekking uit Suid-Afrika weer vas te stel wat die relatiewe posisie van Apple tans is, veral teenoor byvoorbeeld IBM PC en Olivetti wat in die laaste tyd baie sterk op die voorgrond getree het.

\section{Koste van mikrorekenaarstelsel}

Die kosteverspreiding word skematies in Figuur 2 getoon. Uit hierdie figuur is dit duidelik dat ongeveer $65 \%$ van alle 


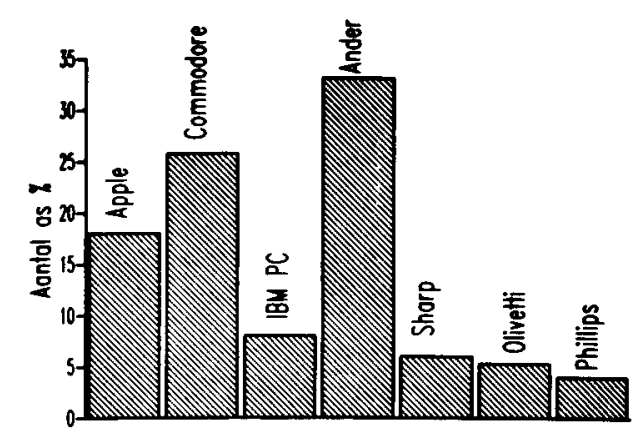

Figuur 1 Tipe mikrorekenaar.

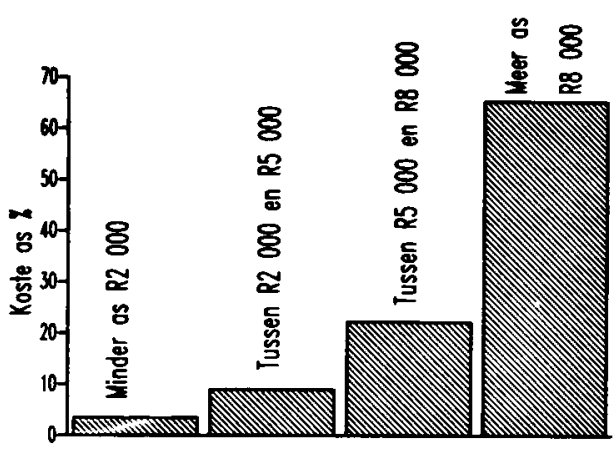

Figuur 2 Koste van die mikrorekenaar.

mikrorekenaarstelsels vir 'n koste van meer as R8 000 aangekoop is. Dit sluit natuurlik die programmatuur ook in wat vir baie gevalle redelik groot bedrae beloop het. Van die klein sakeondernemings het hulle programmatuur spesiaal laat ontwikkel - 'n faktor wat 'n groot rol in die totale pryspakket gespeel het.

\section{Hoofrede vir die aankoop van die mikro}

'n Pertinente vraag by die outeurs was wat die hoofrede vir die aankoop van 'n mikrorekenaarstelsel by klein sakeondernemings is. In die gemelde voorondersoek het geblyk dat ' $n$ wanvoorstelling deur die agent in baie gevalle die rede was. Agente was in sommige gevalle geneig om die vermoëns van die mikro so voor te stel dat dit verwagtinge by die bestuur van die sakeonderneming gewek het wat later nie nagekom kon word nie, met as gevolg'n geweldige negatiewe instelling teenoor rekenarisering.

In hierdie projek het die oorgrote meerderhied van die respondente $(51,4 \%)$ gemeen dat 'n mikrorekenaar hulle administratiewe werk sal verminder. Administratiewe beheer is deur $27,8 \%$ as hoofrede vir die aankoop van die rekenaar gegee. 'n Moontlike verklaring vir bogenoemde is die feit dat dit mag wees dat 'n groot persentasie van klein sakeondernemings van burodienste gebruik gemaak het voor die aankoop van die mikro.

\section{Tydsverloop voordat die eerste probleme ondervind is}

Met konsultasieprojekte deur die eerste outeur in klein sakeondernemings het dit geblyk dat die bestuur geweldig baie probleme met hulle stelsels ondervind het. Dit het ook uit die voorondersoek geblyk. In hierdie projek is daar ook 'n vraag ingesluit waar die onderneming ' $n$ aanduiding moes gee van die tydsverloop voordat die eerste probleme ondervind is. Interessant om te merk dat $54,8 \%$ van die klein sakeondernemings wat probleme met die stelsels ondervind het, dit binne die eerste twee weke ondervind het.

Van die sakeondernemings wat probleme ondervind het, het $46 \%$ programprobleme, $23 \%$ apparatuursprobleme, $17 \%$ probleme as gevolg van onkundigheid omtrent die stelsel en $14 \%$ probleme as gevolg van kragonderbrekings ondervind.

Baie van bogenoemde probleme kan toegeskryf word aan die mate van rekenaargeletterdheid onder die gebruikers want 'n baie groot persentasie, naamlik $72,2 \%$ van die respondente wat mikrorekenaars gebruik, het geen formele rekenaaropleiding gehad nie. Slegs $0,7 \%$ het rekenaaropleiding op skool gehad, 19,4\% het kort kursusse gevolg, $1,4 \%$ het Techniconopleiding en $6,3 \%$ het rekenaaropleiding op Universiteit gehad.

Van die probleme kan ook wees as gevolg van die opleiding wat aan die gebruikers verskaf is aangaande die bedryf van die rekenaarstelsel. Figuur 5 toon grafies die hoeveelheid opleiding wat verskaf is in die gebruik van die stelsel.

Onrusbarend is hier die feit dat $\pm 27 \%$ van die sakeondernemings geen opleiding omtrent die gebruik en bedryf van hulle stelsel gehad het nie. Ook die feit dat slegs $50 \%$ 'n dag of meer opleiding gehad het. Hierdie feit kan in baie gevalle

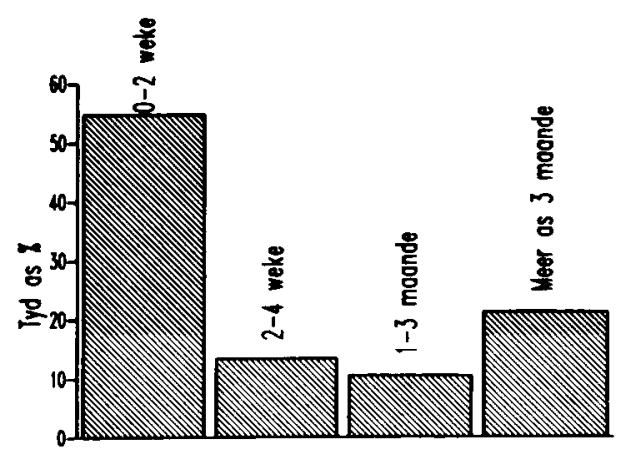

Figuur 4 Tydsverloop voordat die eerste probleme ondervind is.

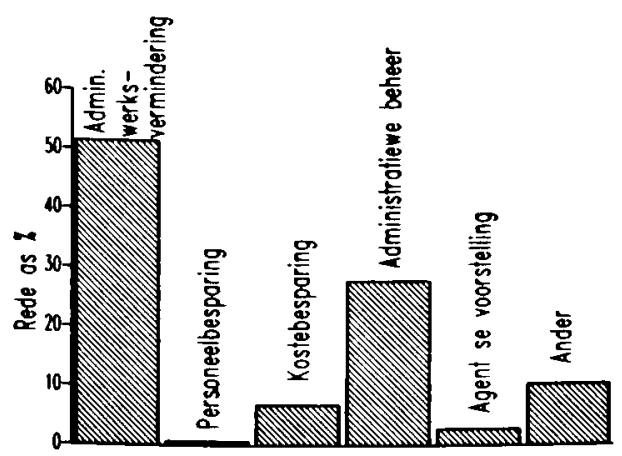

Figuur 3 Hoofrede vir die aankoop van die mikrorekenaar.

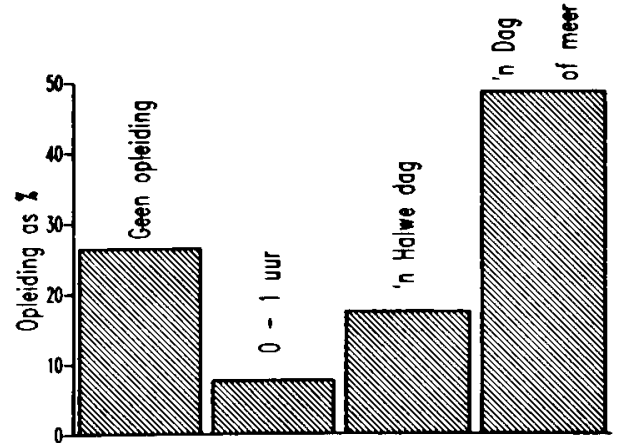

Figuur 5 Hoeveelheid opleiding in die huidige stelsel. 
die hoofrede wees waarom mikrorekenaars nie suksesvol in 'n klein sakeonderneming aangewend kon word nie.

\section{Welslae van die mikrorakenaarstelsel}

Een van die doelstellings van hierdie projek was om vas te stel watter faktore die grootste bydrae lewer tot die welslae van die bepaalde stelsel.

Uit 'n metingsoogpunt was die aantreklikste metode om die welslae van die stelsel te meet, die tevredenheid van die bestuurder met die bepaalde stelsel (Bruwer, 1983; Bruwer, et al. 1983; Bruwer, 1984). Omdat tevredenheid relatief is, is 'n kontinuum (7-puntskaal) gebruik vir die meting daarvan. 'n Meervoudige lineêre-regressieprogram (BMDP9R) is vervolgens gebruik met hierdie welslae of sukses as afhanklike veranderlike en al die ander faktore as onafhanklike veranderlikes.

Deur van hierdie alle-moontlike-deelversamelingsbenadering vir meervoudige lineêre-regressie-analise gebruik te maak, was dit relatief eenvoudig om alle moontlike deelversamelings van verskillende groottes te ondersoek om sodoende dié deelversameling te vind wat die afhanklike veranderlike (in hierdie geval TEVREDE) die beste verklaar. Die maatstaf wat gebruik is, is die gedeelte van die totale variansie van die afhanklike veranderlike as gevolg van 'n lineêre kombinasie van 'n gegewe versameling veranderlikes $\left(R^{2}\right)$. Aangesien 'n aantal veranderlikes in die versameling 'n verhoogde neiging van $R^{2}$ tot gevolg het, is die aangepaste $R^{2}$, naamlik $R_{a}^{2}$, wat hierdie neiging in ag neem, gebruik.

Die deelversameling van veranderlikes uit Tabel 1 wat die afhanklike veranderlike TEVREDE die beste verklaar, is REDE, PROB2, OPL1, ADMIN, AGENT en BESL met 'n $R_{a}^{2}=0,529$. Dit is dus duidelik dat die rede vir die aankoop van die mikro, die tipe probleme wat ondervind is, formele rekenaaropleiding, die mate waartoe administratiewe werk verminder is, die agent se voorstelling van die stelsel en die mate waarin die rekenaaruitvoer in besluitneming gebruik word, belangrike bydraes lewer tot die tevredenheid van die bestuurder en dus tot die totale welslae van die mikrorekenaarstelsel.

\section{Tweerigting-gebeurlikheidstabelle}

Die data is verder ontleed deur van die BMDP4F-program (Dixon \& Brown, 1981:143) gebruik te maak. Dié program gee die aantal voorkomste van 'n gegewe veranderlike teenoor ' $n$ ander in tabelvorm weer. Alle kombinasies van tabelle (144) is ondersoek en slegs die belangrikste bevindinge word genoem

(i) $63,2 \%$ van die sakeondernemings wat probleme binne die eerste twee weke ondervind het, het programprobleme ondervind.

(ii) $76,9 \%$ van die bestuurders wat gevoel het dat die rekenaar glad nie voldoen aan die agent se voorstelling daarvan nie, het probleme binne die eerste twee weke gekry.

(iii) $50 \%$ van die bestuurders wat programprobleme ondervind het, het minder as ' $n$ halwe dag opleiding gehad in die gebruik van die stelsel.

(iv) $57,7 \%$ van dié wat apparatuursprobleme ondervind het, het ook minder as 'n halwe dag opleiding gehad in die gebruik van die stelsel.

(v) $76,9 \%$ van die bestuurders wat gevoel het dat die rekenaar glad nie voldoen aan die agent se voorstelling daarvan nie, het programprobleme ondervind. (vi) $50 \%$ van die bestuurders wat gevoel het die rekenar vergemaklik hulle werk, het 'n dag of meer opleiding gehad, terwyl slegs $16 \%$ van die bestuurders wat teenoorgesteld gereageer het, 'n dag of meer opleiding gehad het.

\section{Bespreking van die resultate}

Mikrorekenaareienaars in klein sakeondernemings ondervind in baie gevalle probleme wat moeilik deur hulle self opgelos kan word. Redes wat hiervoor aangevoer kan word en ondersteun word deur die bevindinge in hierdie ondersoet, is die lae vlak van kennis omtrent rekenaars by die bestuurders van klein sakeondernemings. Verdere bydraende faktore hiertoe is die relatief min opleiding wat ontvang is in die gebruik van die mikrorekenaarstelsel en die skewe beeld wat deur sommige agente geskep word omtrent die mikrose vermoë.

Een of ander vorm van rekenaaropleiding is uiters noodsaaklik vir die klein sakeman indien hy 'n sukses van sy rekenariseringspoging wil maak. Die ondergaan van formele opleiding mag moeilik en nie prakties moontlik wees nie maar daar is alternatiewe wat gevolg kan word. So kan die bywoon van kort kursusse of seminare, selfstudie, advies van kundiges, ens. 'n groot bydrae lewer om die vlak van rekenaarkundigheid te verhoog.

Die aanwending van die mikrorekenaar in 'n klein sake. onderneming kan 'n groot bydrae lewer tot meer effektiewe bestuur deurdat administratiewe take doeltreffend dew hom hanteer kan word. Sy waarde is egter nie net tot administratiewe take beperk nie, maar hy kan baie nuttig aangewend word as 'n beluitnemingshulpmiddel. Diens en naverkoopsdiens deur die verskaffer is egter ' $n$ baie belangrike faktor wat sterk oorweging behoort te geniet wanneer die aankoop van 'n mikrorekenaarstelsel oorweeg word.

\section{Gevolgtrekkings}

Die vlak van gebruik van mikrorekenaarstelsels in klein sakeondernemings in Suid-Afrika is tans nog relatief laag. Dit blyk nie alleen uit die lae persentasie $(14,6 \%$ - wat' $n$ oorskatting kan wees) van klein sakeondernemings wat die mikrorekenaar in hulle ondernemings aanwend nie, maar ook uit die feit dat relatief $\min ( \pm 50 \%)$ van die bestuurders dit in 'n beluitnemingsondersteuningsrol gebruik. Dit is dan heelwaarskynlik ook net inligting wat uit 'n transaksieverwerkingspakket soos debiteure, krediteure, voorraadbeheer, ens. voortspruit wat met gerekenariseerde stelsels verwerk word. Talle ander pakkette wat spesifiek ontwerp is om die bestuurder in sy besluitneming te ondersteun is reeds beskikbaar op die meeste mikrorekenaarstelsels. Sodanige programmatuur behoort nuttig gebruik te kan word deur klein sakeondernemings om behoorlike beplanning te doen. Dit geld nie slegs vir kort- en mediumtermynbeplanning nie, maar ook vir strategiese beplanningsdoeleindes.

\section{Summary}

Computers, and especially microcomputers, are at present playing an increasingly important role in the business world. In the past data processing was mostly done manually, but this tendency seems to be changing very rapidly as the low costs and power of the microcomputer are enabling the small businessman to afford his own computer system to an increasing extent.

Unfortunately this change-over causes manv nroblems to 
the manager of a small business concern, and the causes of these problems are not always easy to identify. Mr. Fred Amport, Director of Information Management Consulting Services (Chicago, USA), once quoted. 'Virtually any company can profit from a computer - provided the commitment is made intelligently, but the odds are 50/50 that it won't be, at least not the first time out.'

It seems that when trying to implement a computer-based system, not only will things go wrong, but a good percentage of the time the system will not be implemented at all!

Many problems may arise if the manager does not follow the correct procedures before switching over to a computer. There are also a number of basic steps to be followed after implementing a microcomputer. Lack of formal computer training and training in the use of the implemented system by the salesman are identified as two of the major obstacles in the successful implementation of a microcomputer system.

\section{Verwysings}

Bruwer, P.J.S. 1983. Faktore wat die werkverrigting van rekenaargebaseerde inligtingstelsels beïnvloed. S. $-A f r$. Tydskr. Bedryfsl., vol. 14, 6.

Bruwer, P.J.S., Pretorius, C.E. \& Steyn, H.S. 1983. MIS problems in a batch processing environment. S.-Afr. Tydskr. Bedryfsl., vol. 14, 172.

Bruwer, P.J.S. 1984a. A descriptive model of success for ComputerBased Information Systems. Information and Management., vol. 7, No. 2. Amsterdam: North Holland Publ. Co.

Bruwer, P.J.S. 1984b. User satisfaction, user attitudes and the success of a Computer-Based Information System. Proc. of Int. Comp. Symposium, Vol. 1, Tamkang University, Taipei, Taiwan, p.189.

Lucas, H.C. Jr. 1975. Why information systems fail. New York: Columbia University Press.

Dixon, W.J. \& Brown, M.D. 1981. BMDP-81, Biomedical Computer Programs, P-series. 2nd Edition. Berkeley, Los Angeles: University of California Press. 